\title{
Génétique moléculaire de deux maladies neurologiques héréditaires de la souris
}

Au cours du développement, les axones s'entourent d'une gaine de myéline sous la direction de cellules d'origine gliale, les oligodendrocytes dans le système nerveux central (SNC), les cellules de Schmann dans le système nerveux périphérique (SNP). La myélinisation comporte l'activation de gènes spécifiques; l'analyse des principaux de ces gènes et des protéines dont ils dirigent la synthèse vient d'être exposée dans un article de Lemke [I]. Les protéines majeures sont au nombre de trois : la protéine basique de la myéline présente, à la fois au centre et à la périphérie, mais à un taux beaucoup plus élevé dans le SNC, la protéolipide protéine et la glycoprotéine $\mathrm{Po}$, spécifiques, la première $d u S N C$, la seconde $d u$ SNP. Une découverte récente importante est que dans deux maladies neurologiques héréditaires de la souris (dont l'une a peut-être un analogue chez l'homme) on a trouvé des altérations des gènes de deux de ces protéines.

On sait qu'il existe plusieurs types de telles affections [2]. Elles sont définies sur les plans clinique, anatomique et biochimique mais jusqu'à l'an dernier aucune interprétation moléculaire n'avait pu être fournie.

Protéine basique de la myéline et mutation shiverer.

Cette protéine est une molécule très basique, présente, du moins chez la souris, sous la forme de plusieurs protéines allant de 14 à 21 kilodaltons. L'obtention de clones génomiques et d'ADN complémentaire a permis de montrer qu'il n'existe qu'un seul gène (localisé chez la souris sur le chromosome I8), dont certains des sept exons sont ou non exprimés dans chaque protéine par suite d'épissages différentiels. Chez la souris shiverer (qui comme l'indique son nom présente des tremblements, suivis de crises convulsives), Roach et al. (Caltech, Californie) ont démontré [3] l'existence d'une délétion importante qui a fait disparaître le gène entier à l'exception de l'exon I et du début de l'intron I. La protéine basique fait donc complètement défaut. Il en résulte une structure tout à fait anormale de la myéline; il faut noter que les anomalies sont beaucoup plus marquées dans le SNC que dans le SNP : cette différence est due à la présence, dans ce dernier seulement, de la glycoprotéine $P o$, majoritaire dans la myéline des nerfs périphériques. Cette protéine de 28-30 kD a été clonée par Lemke et Axel [4]; elle semble pouvoir se substituer fonctionnellement à la protéine basique de la myéline. Son déficit n'a pas encore été décrit.

Protéolipide protéine et mutation jimpy.

La protéolipide protéine (PLP), aussi appelée lipophiline, est le constituant principal de la membrane dans la myéline centrale. Son expression est limitée aux oligodendrocytes et à la myéline du SNC. Elle est très hydrophobe, sa taille apparente est de 26-30 kD, elle contient des lipides mais pas de glucides. Un travail franfais remarquable, qui associe des équipes parisiennes et marseillaises [5], a décortiqué la génétique moléculaire de la PLP et montré ses relations avec la mutation jimpy de la souris. On savait déjà que le caractère jimpy est lié au chromosome $X$. Les auteurs ont d'abord montré qu'une sonde d'ADNc correspondant à la PLP réagit uniquement avec l'ADN du chromosome $X$ et en ont localisé le gène de façon très précise. Combinant l'analyse de l'ADN avec l'étude génétique de pedigrees de souris normales et mutantes, ils ont conclu que le locus jimpy était vraisemblablement le même que celui de la PLP. La mesure de l'ARN messager dans le cerveau de souris normales et jimpy en montra l'effondrement chez les mutants. L'anomalie du gène de la PLP fut confirmée par des expériences de protection à la nucléase SI, démontrant qu'il existe probablement une délétion dans le gène; mais cette délétion est certainement beaucoup plus petite que celle du mutant shiverer car elle n'est pas détectable sur des expériences du type Southern.

L'intérêt de la découverte de l'anomalie moléculaire de la souris jimpy est encore renforcée par les anologies anatomo-cliniques de ce mutant avec une maladie humaine liée au sexe, la maladie de Pelizaeus-Merzbacher [6], marquée dès le début de la vie par un retard mental accentué, une ataxie cérébelleuse, une leucodystrophie progressive et une démyélinisation cérébrale.

J.-C. D.

I. Lemke G, Molecular biology of the major myclin genes. Trends in Neurosciences 1986; 9: 266-70.

2. Baumann N, ed. Neurological Mutations Affecting Myelinisation. Amsterdam: Elsevier North Holland Biomed Press, 1980.

3. Roach A, Takahashi N, Pravtcheva D, Ruddle F, Hood L. Chromosomal mapping of mouse myelin basic protein gene and structure and transcription of the partially deleted gene in shiverer mutant mice. Cell 1985; 42: 149-55. 4. Lemke $G$, Axel R. Isolation and sequence of a cDNA cncoding the major structural protein of peripheral myelin. Cell 1985; 40: 501-8.

5. Dautigny A, Mattei MG, Morello D, et al. The structural gene coding for myclin-associated protcolipid protein is mutated in jimpy mice. Nature 1986; 321: 827-9.

6. McKusick VA. Mendelian Inheritance in Man. Baltimore: Johns Hopkins University Press, 1983 ; p. 1087 , item 31160 . 